\title{
Human Resource Role in Change Management during Cross Border Mergers
}

\author{
Dr. Fareeha Zafar ${ }^{1}$, Yousaf Iqbal' ${ }^{2}$, M. Tahir Azad ${ }^{3 \text {, and }}$ Rao Jameel Afsar ${ }^{4}$ \\ ${ }^{\prime}$ (Computer Department, GCU Lahore, Pakistan) University of Derby, currently working in GCU, Lahore \\ ${ }^{2}$ (IBM, UET Lahore, Pakistan) \\ ${ }^{3}$ (IBM, UET Lahore, Pakistan) \\ ${ }^{4}$ (IBM, UET Lahore, Pakistan)
}

\begin{abstract}
Human resource in today's age and time has a strategic role to be played in change processes. The following paper analyzes the key factors that can lead for a successful merger and how HR can assist in this change. The 2C's namely culture and communication holds the key for success and failure depending upon the implied strategy by the top management and its application by the HR department. Moreover, change management and mergers have been analyzed with case studies from cross border mergers.
\end{abstract}

Keywords: Change management, Communication, Cross border mergers, Human resource

\section{INTRODUCTION}

The objective of this paper is to analyze HR role in cross border mergers. In an international merger, two distinct entities come across to meet common objective of increasing shareholder's equity. Now the question arises, Does this change leads to desired synergy or its ends up in a chaos? What are the key factors that should be analyzed to bring in the right mix for a win-win situation? And most imperatively, what role can HR play in this transition as it is the HR that's responsible for looking at the people side of the change. Keeping in view the study limitations, this particular paper will highlight the key functions of HR with respect to change management and later we will study how HR plays its role during successful international mergers. A strong emphasis is given on communication and transformation of ideas by change agents into actions to motivate front line employees. These front line managers actually hold the key because they receive the major change impact. They remain under influx of this peculiar feeling of uncertainty and stress.

Therefore, a strong one to one communication, taking into their legitimate concerns, giving them an opportunity to take part in the change process, envisioning them a bright future is all that's required in routine. Yet, companies have to be more reluctant and vigilant in cross border as norms, values and ethical behavior changes with the demographic change from one place to another. That's the reason why the HR role become vital in success or failure depending upon their focus and sensitivity of the minor issues that often goes under the table without anyone noticing under major talks and changes. There are three main parts of this paper. In the following lines, we have analyzed HR, its functions, importance and its role during mergers.

\section{Human Resource:}

Human resource management is the management process of organization's workplace or HR. In short, it is responsible for attraction, selection, training, and assessment and rewarding of employees. Retrospectively, HR was concise only to payrolls, benefits and more eloquently something that serves as a bridge in between industry and labor. In today's age and time, the new role of HR is more of strategic initiatives with top leadership and transforms the culture into an organization:

1. Diversity and inclusion

2. Industrial and labor relations

3. Succession planning

4. Talent Management

5. Mergers and Acquisitions

The most imperative function of HR is still talent retention and knowledge workers. That's because we are dealing with humans and human behavior studies depict that it is attetion and employee enagegement that leads to satisfaction as analyzed by Hawthrone studies.

2.1 Key functions of Human Resource: According to David Ulrich, there are four key functions of HR:

1. Aligning HR/ Business Strategy

2. Re-engineering Organization Processes

3. Listening and responding to employees

4. Managing Transformation and Change [1] 


\subsection{Importance of Human Resource:}

Human beings are selfish by nature and they tend to behave differently in different socio-economic backgrounds or scenarios. We can bring change in the systems, processes or technology but it's worthless if you do not have the human resource to operate it or have enough training to sustain with the change. Therefore, human resource is not only important in bringing change from one's present state to the future by envisioning the bright side, it is critical for daily operations. Motivation, commitment, going extra mile, thinking out of the box, determination and ability to critically think are characteristics that make humans unique and extra special in any sphere of the world. According to the principles of change management, it is the people side of the change that is more critical instead of focusing on the hard factors like finance, systems and procedures.

HR is playing a very important role in human life. It has different method and technique to make and buy decision. HR manager see the employee competency in an effective and efficient manner and he maximize the profitability. Company sees his employee engagement to his work. HR does accountability of employee who does not work sincerely. HR enhances the value and work on development of the human capital. HR expert help the top leadership in making strategy. They make the understanding of the business.

The drive for revenue growth puts unique demands on an organization. Companies seeking to acquire new customers and develop new products must be creative and innovative, and must encourage the free flow of information and shared learning among employees. They must also become more market focused - more in touch with the fast changing and disparate needs of their customers. And companies seeking growth through mergers, acquisitions, or joint ventures require other capabilities.

Knowledge has become a direct competitive advantage for companies selling ideas and relationships and an indirect competitive advantage for all companies attempting to differentiate themselves by how they serve customers. From now on, successful companies will be the ones that are the most adept at attracting, developing, and retaining individuals who can drive a global organization that is responsible to both its customers and the burgeoning opportunities of technology.

As one of the main barriers for the ability of HR professionals to play a more strategic role in an organization is their lack of certain competencies (Aitcheson, 2007). In general, competency is defined as a personnel-related concept referring to a set of behavioral dimensions of HR professionals' effective performance at work. Some authors suggest more precise definitions that describe competencies as the work-related personal attributes: knowledge, skills, and values that individuals draw upon to do their work well. These elements, at the same time, are the factors that enable assessment, feedback, development, and reward for individuals to take place (Kochanski, 1996).

\section{3 e-HR:}

Ideas and massive amounts of information are in constant movement. The challenge for managers is to make sense and good use of what technology offers. Managers will need to figure out how to make technology a viable, productive part of the work setting. Human resources professionals need to be able to leverage technology for HR practices and use e-HR/web-based channels to deliver value to their customers (Mukherjee, 2001). Mukherjee (2001) further argues that the pace of technological innovation will continue to accelerate. HR can take advantage of these changes by automating HR processes and becoming more effective in communicating with internal/external customers. More importantly, by absorbing the latest technology, HR can project a forward-looking image that will help it earn the respect of skeptical colleagues.

According to a recent survey by the Society for Human Resource Management, the top workplace trend identified was technology (Mondi \& One, 2005). Some of these trends include increased web-connected workplaces, Outsourcing of functions to individuals and firms throughout the world, virtual workplaces (Such as online meetings, web conferences, and videoconferencing), using analytical tools to measure the success of HR practices, predicting future results, and contingency planning, such as planning for disaster. A major commitment among forward-looking organizations is being made to increase the use of e-HR (Mondi \& One, 2005).

\section{Change Management:}

Change is everywhere around us, it's a vital life sign, a rule of nature, space and time. You have to constantly strive hard to innovatively work while keeping your standards high and cost low that's efficient and yet competitive in this global arena. Therefore, you have to change rapidly and accordingly to compete effectively. "Change management is an approach to transitioning individuals, teams, and organizations to a desired future state." [2] In simple words, change management deals with a continuous process of transition from present to future state. According to Mr. Kottler, there is a difference in between change management that tries to keep things under budget, monitors the changes if they are going according to plans and change leadership. He describes the difference as, "Change management refers to a set of basic tools or structures intended to keep any change effort under control. The goal is often to minimize the distraction and impact of the 
change. Change leadership, on the other hand, concerns the driving forces, visions and processes that fuel large scale transformation". [3]

Change Management is imperative today because of the rapid development in technological innovation, globalization, social media inception, and mobile adaptability. However, we have to keep the difference in mind when we talk about change leadership and change management. The basic difference in between the both is their essence. Change management deals with operational part of the change. It answers the questions like if things are in control while changing. However, change leadership takes into account a complete transformation of large scale changes in quick time by taking leaps and higher risks.

\subsection{What, why and how of Change Management:}

Responsiveness to change is the key of success or failure. In today's competitive world, change is the only way of life and those who are not responsive to change may not last longer. Change is leading itself because it's a process not an event. In words of Charles Darwin, "It is not the strongest of the species that survives nor the most intelligent, but the one most responsive to change." [4] Companies that understand this notion does not follow the status quo and they are ones who capture the major shares in any given businesses.

\subsection{Change Processes:}

Change process can be of two types, autonomous (internally driven) or Induced (revolutionary changes due to change in technology). This process covers four broad areas including, creation, growth, transformation and decline. We will discuss induce strategy that begin with questioning the current state of actions. In the second phase, it brings in new approaches by suspending the current policies and at last consolidates after the new approaches become accustomed and accepted by the employees.

\subsection{Change Process Theories:}

There are three main renowned theories:

3.3.1 Beckhard and Harris three part theory model: "present, transition and future".

3.3.2 Lewis and Scheins: "Unfreezing, changing and refreezing"

3.3.3 Tichy and Devanna's model of: "Awakening, mobilizing and reinforcing”. [5]

\subsection{Resistance:}

Why people resist? Paul Sterbel conducted a research on 200 managers from 32 countries writes in his article, "Why do employees resist change? Personal Compact" published by the Harvard Business Review, June 1996 [6]. There is one common root cause of resistance that is both manager and employees views change from a different perspective. Therefore, there is a natural gap and those who successfully bridge it, lead the change while others fail. People resist change because they view it as an ambiguous state of mind where they are not clear about their specific role and more importantly how this role will be rewarded or evaluated both financially and psychologically. Mr. Sterbel gives three dimensions of personal compacts including
i. Formal (Job description/rewards)
ii. $\quad$ Psychological (implicit relationship like trust among employer and employee)
iii. Social perspective (an employee's commitment to the organization based on its cultural values and norms).

Therefore, a natural conflict of interest arises and if the rewards/consequences are not properly communicated, it can lead to failure. That's why according to the practitioners, "the success rate of change in 1000 Fortune companies to carry change successfully has been less than $50 \%$ or even closer to $20 \%$ ". [7] 3.5 Managing change resistance:

There is no right or single answer to this question because we are dealing with humans and that's the most difficult thing. In an article by John Jones, De Anne Aruiree and Mathew Caldrone, "10 Principles of Change Management": Tools and techniques to help companies transform quickly, April 15, 2004, Harvard Business School, Executive Education [8]. They summaries the way to mitigate the resistance: These include:

1. Address the human side

2. Start at the top

3. Involve every layer

4. Make the formal case

5. Create ownership

6. Communicate the message

7. Assess the cultural landscape

8. Address culture explicitly

9. Prepare for the unexpected 
10. Speak to the individual

\subsection{Leadership - Change Agents - The Real Impact:}

The top management transforms its vision which they think is better for the future course of action for the stake holders while the middle management is the one who has to transform this vision into a mission. They break down the broader perspective into plans for the front line managers working at the bottom of the pyramid. This transformation of ideas from top to bottom seems very simple on the face of it but here comes the role of HRM who's responsibility is not only hire, train and retain employees but also make sure that everyone is on the par value through efficient and effective communication.

The question arises, How to create a powerful vision for change? It is the leadership (top management) that envisions the broader picture and motivates the change audience through change agents. This change vision can be a message spread around by the HR department. It should be a quick, precise and clear communication that can be understood by a wide range of people.

\section{Mergers:}

The trend of mergers has become a very much popular form of corporate development for the purpose of growth and diversity. Mergers are considered to be important part of both healthy and weak economies and mostly the prime way by which companies are capable to provide returns to their investors, stakeholders and owners. In a merger, the corporations combine together and share their resources to achieve their common objectives. The shareholders of the combining firms mostly remain as joint owners of the combined entity. Mergers seem to be an enormous effort of two firms to come together into one corporate entity with a common vision, mission and objectives. The core purpose of this activity is to go for a radical change in both of their operating performance by way of developing stronger competitive strengths and synergies. [9]

The word MERGER can be takes as abbreviation which means.

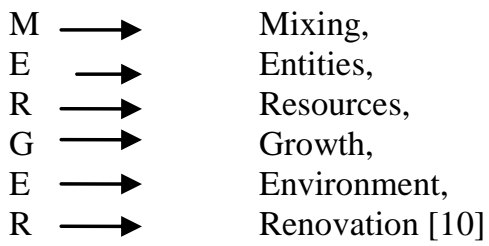

4.1 Types of Mergers:

4.1.1 Vertical

4.1.2 Horizontal

4.1.3 Diversification/Conglomerate

4.1.1 Vertical Mergers:

Vertical mergers are combinations of firms, who have a buyer-seller relationship or are symbiotically related. These mergers takes place when companies that are involved in related functions but at different phases in the production process merge with one another.

\subsubsection{Horizontal Mergers:}

Horizontal mergers, occurs when companies performing similar functions merge to increase the scale of their operations. Horizontal mergers are firmly controlled by governments because of the adverse effects on competition. BMW- Rover, VW- Rolls- Royce and Daimler Chrysler merger are the horizontal mergers in the automotive industry.

\subsubsection{Diversification/Conglomerate Mergers:}

Diversification occur when one company acquire one or more companies that are neither exchange partners nor similar companies competing with each other, but companies operating in different areas. The extreme form of diversification is the conglomerate. [11]

\subsection{Cross Border Mergers and HR:}

"Cross border mergers are used as a mean for gaining entry into foreign market, a method of engaging in dynamic learning process, or a value creating strategy" [12]

In today's global arena led by innovators and high tech gurus blended with best practices, Mergers and Acquisition is natural phenomena to create synergy and win-win situation. A successful merger across international geographical boundary requires a right blend of leadership skills, tools and techniques, supported and implemented by HR's diligent, precise yet detailed working catering the global needs by considering local 
facts. HR has to take account of key issues that pops up during a cross border merger. These may include cultural differences, diversity, customs, rituals, inclusion, and set of ethical values and shared norms.

HR responsibility is not only to understand the dynamics of across border variables as listed above but also proactively take preemptive measures to regulate, train, communicate, and at times revamp any catastrophic changes at their initial level to avoid chaos. Considering HR basic role as the mediator in between industry and labor regulation, it become evident for HR to serve or provide a common platform for both companies who are in the transition to settle their human side issues.

It is HR who becomes responsible for bridging the gap by joining missing links at both levels in order to create a new shared vision and an environment that's inclusive [13] and respect diversity in a newly born culture from the top management.

4.3 Mergers Objectives:

Following are the main objectives which attracts the companies for merger.

1. Appropriate use of all the available resources.

2. Prevention of the exploitation of unutilized and underutilized assets and resources.

3. Formation of a strong human base.

4. Reducing the tax burden.

5. Profit improvement.

6. Eliminating or limiting the competition.

7. Achieving savings in monitoring costs. [14]

\subsection{Mergers and Corporate Culture:}

The Merging companies have to face the change in cultural difference which is known to be very ordinary reason for merger failure, reinforced when it comes in cross border combinations. Definitely, both of these partners incorporate in the new merged company the national and the corporate cultures. Therefore, in order to be successful, the leaders and HR have to consider the significance and the influence of these issues perfectly during the post-merger integration process, at the same level as the synergies, business performance and profit improvement.

It is very much understandable that when two different companies with different background, histories and ways of working get together they might face cultural change. The acquiring company has to capture the full value of the merger by integrating carefully each element of both organizations. The development of a new and shared culture is one of the most critical factors for merger success. So, the preliminary challenge for all the organizations which consider a merger or acquisition is to understand that the culture has very deep roots which cannot be easily pulled out, studied and reprogrammed to create a new shared set of culture. Creating a shared culture involves careful discovery, formulating, reseeding and letting to.

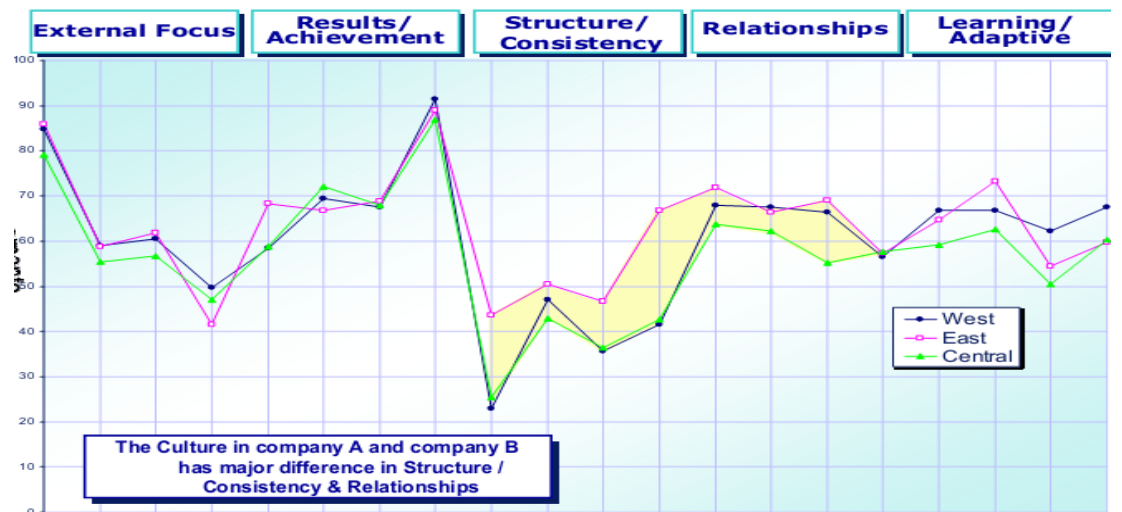

Figure 1: Identify cultural differences and formulate a desired state

Source: The Role of Corporate Culture within Successful Globalization Strategies

Additionally, there is no need to argue for the importance of corporate culture on organizational behavior and performance. Researchers (e.g. Bennis and Nanus 2003, Shein 1999) argued comprehensively for corporate culture as the crucial factor for successful organizational development during mergers and acquisitions. The corporate culture requires careful attention. It is an essential process of managing an organization to establish the correct and proper culture. Merging at an international level meaning to create a new shared vision and culture driven from the top that's slowly seeps at the bottom and at every hierarchical level of an organization. From bottom-top, each member should be clear about the new culture driven by the new holdings. The new leadership has to strategically involve its HR from both sides to understand the norms and communicate their new set of priorities. 
Let's briefly touch upon the concept of culture and how it can build during mergers. Kottler, J. (Sep 27, 2012), "The Key of Changing Organizational Culture", Forbes online, defines Culture as "Culture consists of group norms of behavior and underlying shared values that help keep those norms in place". [15] Organizational culture is driven from the founders of the group and its builds up due to the success and appreciation of their brain child. Now, when an international mergers occurs it become vital to clear the camouflage state of new culture as a result of this merger. The new culture will be brought up by the new leadership. They are the one whom are looked upon for new change vision. If the new actions produce better results, appreciated and communicated, they will become norms and gradually grow into shared values.

Now looking at the other side, what are the factors that don't let things blend up in cross border merger? In the perspective of building a new culture, the things that prevent from shaping things up can be a group within an organization. These are usually the union or pressure group that decides what will be the norms or culture. In the Compaq and HP merger, Barbara Braun, the vice president for merger integration at HP spoke that:

"The easiest thing to do with culture is to simply chose one company's culture as dominant", "However, we believed it was important to get the best of both $H P$ 's engineering culture and Compaq's marketing culture. We wanted to blend the best of both cultures to create a new culture for the merged company. " [16]

\subsection{Success and Failure Case Studies: \\ 4.5.1. Successful Merger:}

Cloetta Fazer: Cloetta was founded in 1862 in Copenhagen by three brothers Christoffer, Nuttin and Bernhard Cloetta belong to Switzerland. In 1891, Karl Faer opened his French Russian Bakery in Helsinki, to finally in 1897: start with the industrial production of the confectionary. On the $1^{\text {st }}$ of January 2000, Swedish Cloetta and Finish Fazer Konfektyr got merged. Cloetta Frazer's mission is to create joy and delight, to all people, irrespective of age of preference in taste, shall delight of the company's wide range of chocolate and confectionary.

Cloetta Fazer acknowledged the significance of organizational culture in achieving all functions and the merger work. Cloetta Fazer did not perceive the culture differences as a immense threat in developing the structure of the organization, as people find each other no matter if they came from India, England or Sweden, as you have to work in common. The merger success met by Cloetta Fazer is not hazardous; numerous factors were involved in the favor of the integration process. Firstly, both companies were considered each other as equal during the merger, there was no intention to take over the control of the new organization. The deal was very much clear from both the companies. Also, the pre-merger has been vigilantly prepared from both sides.

They studied each department carefully in order to represent the possible opportunities and to achieve the possible synergies. Furthermore, Cloetta Fazer shaped a corporate identity which distinguishes, partly, the corporate culture. Therefore, each of the employees could refer to the new shared values. People were responsive of the existence of a new corporate culture with new vision and direction. Plus, Cloetta Fazer acknowledged the importance of human factor by identifying the different competencies and the key individuals in order to integrate them efficiently for better results. Also, the social issues were handled in a peaceful atmosphere and both sides were able to compromise when necessary. Similarly, they planned conferences between top-executives to first highlight the best practices from both sides that existed before the merger and then to understand why they were better in that field. Then these practices were implemented in the whole organization.

\subsubsection{Failed Merger: DaimlerChrysler}

On the 7th of May 1998 the DaimlerChrysler merger was announced after a \$38 billion stock deal. The merger was declared as "a merger of equal". The DaimlerChrysler would be incorporated in Germany with two headquarters in Stuttgart and Michigan. Chrysler Corporation, located in Michigan was founded by Walter P. Chrysler in 1925 in USA. This company is an American automobile manufacturer. On the other hand, Daimler AG was located in Stuttgart, Germany. It is a German car corporation specialized in luxury cars with several other activities.

The heavy presence of cultural conflicts and differences which leaders didn't take seriously and problems between both managements did not help the company to reach the initial goals. However, the leading drawback was that the merger between Daimler and Chrysler in fact "was never truly a marriage of equals." The Chrysler's management had trust blindly in the merger of equals and did not realize the fact of the attempt of Daimler to take over the entire organization. This aspect of the DaimlerChrysler merger has truly affected the success of this merger. It had created an untrusting atmosphere and locked the Chrysler employee's 
involvement in the cultural integration. Consequently, leaders have not taken into account this human factor and have left their anxiousness, fears and concerns without any solid measure.

Then, the national culture had also played a major part in the failure of merger as the corporate cultures are influenced and driven very much by the country's culture. It is risky to underestimate cultural issues in any type of merger, but when the merger involves two companies from different national cultures, those issues become worse and unless a company is prepared they can be devastating which happened in the case of Daimler-Chrysler. Indeed, Daimler-Chrysler did not study the possible source of cultural clashes. Also, the German's lack of integrity from taking the cultural mismatches into consideration led the company to the failure. Daimler had rather impose its own culture on the entire group. [17]

\subsection{Successful Merger Strategy:}

Merger is a strategic plan which brings change that requires thoughtful implementation planning, management, and resources. Mergers of any level are difficult, mainly because of people, technology, and culture. By creating a dynamic vision, supported from the top to the bottom and across silos the success rate of the mergers can be increased. That requires integrated participation at all levels of the organization. [18] The more similar the firm - level strategies of two merging companies (growth, $R \& D$, management), the more likely the merger will be successful. [19]

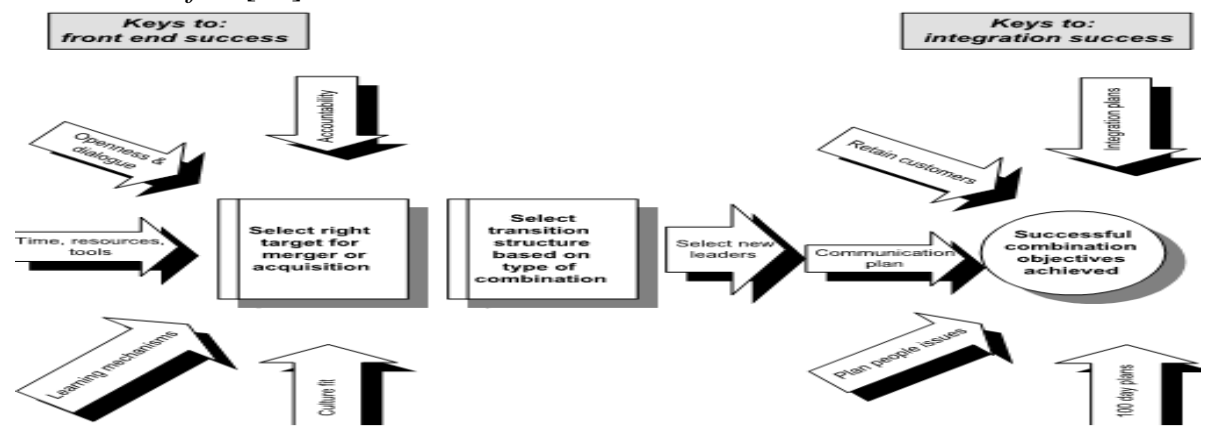

Figure 2: A systems approach to successful mergers and acquisitions

Source: Making mergers and acquisitions work, 2002

A strategy is an integrated and synchronized set of commitments and actions intended to exploit essential competencies and gain a competitive advantage. When company selects a strategy, makes choices between competing alternatives. In this sense, the chosen strategy clarifies what the firm intends to do as well as what it does not intend to do. Moreover, effective due-diligence processes including the deliberate and careful selection of target companies and an assessment of the relative health of those companies (cultural fit, financial health and the importance of human resources) contribute in the success of mergers.

\subsubsection{Pre-Merger Integration Planning:}

The better the strategic fit between the two corporations, the easier to be successful. The pre-planning phase and screening is a critical success factor for mergers. The more planning prior to mergers is better, since the pre-planning phase will affect all business zones and how the integration is handled. It is very important that the merger -planning has a clear understanding of the acquired company's role in the strategy after the merger. The proposition advocates that the more alike the corporations' strategies are, the more likely the merger will be successful. Failures in mergers can be caused by the lack of consideration of different features in the pre -merger phase. Management objectives could therefore also be a significant firm-level factor in the analysis.

\subsubsection{Post-Merger Integration Process:}

Signing the merger contract and the change in ownership brings changes in organization and leadership. Now is the time that a new organization should be placed, appoint new management, and make sure that key talent is retained. [20]

\subsection{Building the New Culture:}

The organizational culture plays a vital role during mergers as the managerial styles, organizational practices and structures to a great extent are determined by the organizational culture. The new organization will have a culture, whether it is by default or by design a culture that may be distinct by conflict or a culture that may be strongly accepted. The procedure of building the new culture goes on long after the combination phase. Enterprises should openly discuss their respective business cultures to determine whether a suitable fit is even possible. Differences must be recognized, accepted and should be dealt. 


\section{Communication, Communication and Communication:}

Communication always plays an important part of any process of change, but it is more critical in cross-border merger because misunderstandings regarding the cultural differences and distance may exaggerate tensions. During the merger clearly defined communication strategy plays an important role in eliminating the employee fears and kill rumors floating around in the organization. The meeting among employees in small groups as to discuss their concerns and positive feelings also helps to minimize the stress on acquired firm employees. This thing can built the mutual trust among employees and also gives them confidence that the new management is ready to listen their feelings and concerns. . The transition period also becomes essential from the communication point of view. In the case of extensive transition period stress level of employee's rises, to realize the employees that they are part of newly formed organization and their concerns will be given importance can be a best strategy in this period. The transition period provides ample opportunity HR to design the new organization, explain the employees new roles, plan synergies and train the employees as the new role. This thing makes the integration process easier for both of the merging organizations. Companies often face resistance from the middle management, uncertain about their new roles, job descriptions and perks. That's one big reason for middle management to resist against any change.

This argument is supported by a research study by Harold, Perry and Alan in their article on, "The hard side of change management" published in Oct 2005 by Harvard Business Review. It says: "A great deal has been said about middle managers who wants to block change. We find that most middle managers are prepared to support change efforts even if doing so involves additional risk. However, they resist change because they don't have sufficient input in shaping those initiatives. Too often they lack tools, the language and forums in which they can express their legitimate concerns about the design and implementation of change projects." [21] The two words above language and expression of legitimate concerns holds the key here. This is lack of communication and one major reason for resistance apart from others.

\section{Conclusion:}

Cross border mergers is strategic move by the top leadership in order to create synergy and gain financial benefits. Its success mainly depends upon the some of the key factors that include, mitigating and realizing cultural difference, communicating change vision, and building a new set of share values. A new entity takes birth as a result of merger and this change is managed by the HR through communication. The HR role becomes critical because it has to manage this change through application of change processes and build a common ground for the new enterprise.

\section{References:}

[1] Ulrich, Dave (1996), Human Resource Champions, The next agenda for adding value and delivering results. Boston, Mass: Harvard Business School Press. ISBN 0-87584-719-6, OCLC 3470904

[2]-[3] Kottler, J. (July 12, 2011), "Change Management vs. Change Leadership: what's the difference? Forbes online, [retrieved 12/21/11] available:http://www.forbes.com/sites/johnkotter/2011/07/12/change-management-vs-change-leadership-whats-the-difference/

[4] Stephen P. Robbins, Timothy A. Judge and Neharika Vohra: "Organizational Behavior: Organizational Change and Stress Management", (2011) Pearson publication, 14th edition, page: 536

[5] R. Beckhard and R.T. Harris, Organizational Transition, Second edition (reading, Massachusetts; Addison- Welsey, 1987, K. Lewis, Field Theory in Social Sciences (New York, Harper, 1951), E. H. Schein, Professional Education (New York: MC Graw Hill, 1972 pg\# $76-84$ and N. Tichy and M. Devanna, The Transformational Leader (New York Willey 1986)

[6] Paul Sterbel, "Why do employees resist change? Personal Compact" June 1996 published: Harvard Business Review

[7] Paul Sterbel, "Why do employees resist change? Personal Compact" June 1996 published: Harvard Business Review

[8] John Jones, De Anne Aruiree and Mathew Caldrone, "10 Principles of Change Management": Tools and techniques to help companies transform quickly, April 15, 2004, Harvard Business School, Executive Education

[9] "What Explains Mergers' Success Or Failure? The Role of Organizational Structures, Strategies and External Environments in Mergers - Empirical Evidence from two Contrasting Cases”, M.S. Thesis, Dept. Science and Technology, Oslo Uni, pp. 52012.

[10] A. Malhotra, "Conceptual Framework of Merger and Acquisition", pp. 6.

[11] "What Explains Mergers' Success Or Failure? The Role of Organizational Structures, Strategies and External Environments in Mergers - Empirical Evidence from Two Contrasting Cases", M.S. Thesis, Dept. Science and Technology, Oslo Uni, pp. 5, 2012.

[12] W. H. Mobley, M.Li, Y. Wang, "Advances in global leadership" 1st ed. Vol 6. WA, UK, Emerlan Group publishing Limited. 2011. ISSBN: 978-0-85724-467-3. Pp 96

[13] Miller, Frederick A. and Katz, Judith. 2002, "The Inclusion Breakthrough: Unleashing the Real Power of Diversity". San Francisco: Berrett-Kochler Publishers.

[14] J. Buckley, N. Ghauri, "International Mergers and Acquisition” London: Thomson, pp. 100-106, 2000

[15] Kottler, J. (Sep 27, 2012), "The Key of Changing Organizational Culture", Forbes online,

[16] "The Secrets of Successful Mergers", Deloitte \& Touche, Usa, Isbn0-9747183-3-5, 2003.

[17] H. Makhlouk And O. Shevchuk, "The Importance And The Influence Of The Corporate Culture In A Merger And Acquisition Context”, M.S. Thesis, Leadership And Management In International Context, Kalmar Uni, pp. 74-99, 2008.

[18] Strategy Implementation, Mccreight \& Company, I Nc. Research \& Operations Center, 2006.

[19] K. Lee and J. M. Pennings, "Mergers and Acquisitions: Strategic - Organizational Fit and Outcomes", 1996.

[20] Evans-Pucik-Barsoux: The Global Challenge, "Forging Cross-Border Mergers And Acquisitions", The Mcgraw-Hill Companies, 2002, Ch. 6, pp. 247.

[21] Harold, Perry and Alan,:“The hard side of change management” published in Oct 2005 by Harvard Business Review 